\title{
Non-linear genetic diversity and notable population differentiation caused by low gene flow of Bermudagrass [Cynodon dactylon (L.) Pers.] along longitude gradients
}

\author{
Jing-Xue Zhang ${ }^{1,2}$, Miaoli Wang ${ }^{2}$, Jibiao Fan ${ }^{1}$, Zhi-Peng Guo ${ }^{2}$, Yongzhuo Guan ${ }^{2}$, Gen Qu ${ }^{2}$, Chuan-Jie Zhang ${ }^{1}$, Yu- \\ Xia Guo ${ }^{\text {Corresp., },}$, Xuebing Yan ${ }^{\text {Corresp. } 1}$ \\ ${ }^{1}$ College of Animal Science and Technology, Yangzhou University, Yangzhou, Jiangsu, China \\ 2 \\ 2 College of Animal and Veterinary Science, Henan Agricultural University, Zhengzhou, Henan, China \\ Corresponding Authors: Yu-Xia Guo, Xuebing Yan \\ Email address: guoyuxia@henau.edu.cn, yxbbjzz@163.com
}

Background. Environmental variation related to ecological habitat is the main driver of plant adaptive divergence. Longitude plays an important role in the formation of plant population structure, indicating that environmental differentiation can significantly shape population structure.

Methods. Genetic diversity and population genetic structure were estimated using 105 expressed sequence tag-derived simple sequence repeat (EST-SSR) loci. A total of 249 C. dactylon (L.) Pers. (common bermudagrass) individuals were sampled from 13 geographic sites along the longitude $\left(105^{\circ} 57^{\prime} 34^{\prime \prime}-119^{\circ} 27^{\prime} 06^{\prime \prime} \mathrm{E}\right)$.

Results. There was no obvious linear trend of intra-population genetic diversity along longitude and the intra-population genetic diversity was not related to climate in this study. Low gene flow $(\mathrm{Nm}=0.7701)$ meant a rich genetic differentiation among populations of $C$. dactylon along longitude gradients. Significantly positive Mantel correlation ( $r=0.438, P=0.001$ ) was found between genetic distance and geographical interval while no significant partial Mantel correlation after controlling the effect of mean annual precipitation, which indicated geographic distance correlated with mean annual precipitation affect genetic distance. The genetic diversity of $C$. dactylon with higher ploidy level was higher than that with lower ploidy level and groups of individuals with higher ploidy level were separated further away by genetic distance from the lower ploidy levels. Understanding the different genetic bases of local adaptation comparatively between latitude and longitude is one of the core findings in the adaptive evolution of plants. 
2 Non-linear Genetic Diversity and Notable Population

3 Differentiation Caused by Low Gene Flow of

4 Bermudagrass [Cynodon dactylon (L.) Pers.] along

5 Longitude Gradients

6

7

8

9

10

11

12

13

14

15

16

17

18

19

20

21

22

23

24

25

26

27

28

29

30

31

32

Jing-Xue Zhang ${ }^{1,2}$, Miao-Li Wang ${ }^{2}$, Ji-Biao Fan ${ }^{1}$, Zhi-Peng Guo², Yong-Zhuo Guan ${ }^{2}$, Gen $\mathrm{Qu}^{2}$, Chuan-Jie Zhang ${ }^{1}$, Yu-Xia Guo ${ }^{2 *}$ and Xue-Bing Yan ${ }^{1 *}$

1. College of Animal Science and Technology, Yangzhou University, Yangzhou, Jiangsu, China

2. College of Animal and Veterinary Science, Henan Agricultural University, Zhengzhou, Henan, China

Corresponding Author:

Yu-Xia Guo and Xue-Bing Yan ${ }^{1}$

63 Nongye Road, Zhengzhou, Henan, 450002, China

NO 48, Wenhui east road, Yangzhou, Jiangsu, 225000, China

Email address: guoyuxia@henau.edu.cn and yxbbjzz@163.com

\section{Abstract}

Background. Environmental variation related to ecological habitat is the main driver of plant adaptive divergence. Longitude plays an important role in the formation of plant population structure, indicating that environmental differentiation can significantly shape population structure.

Methods. Genetic diversity and population genetic structure were estimated using 105 expressed sequence tag-derived simple sequence repeat (EST-SSR) loci. A total of 249 C. dactylon (L.) Pers. (common bermudagrass) individuals were sampled from 13 geographic sites along the longitude $\left(105^{\circ} 57^{\prime} 34^{\prime \prime}-119^{\circ} 27^{\prime} 06^{\prime \prime} \mathrm{E}\right)$.

Results. There was no obvious linear trend of intra-population genetic diversity along longitude and the intra-population genetic diversity was not related to climate in this study. Low gene flow $(\mathrm{Nm}=0.7701)$ meant a rich genetic differentiation among populations of $C$. dactylon along longitude gradients. Significantly positive Mantel correlation $(\mathrm{r}=0.438, P=0.001)$ was found between genetic distance and geographical interval while no significant partial Mantel correlation after controlling the effect of mean annual precipitation, which indicated geographic distance 
35

36

37

38

39

40

41

42

43

44

45

46

47

48

49

50

51

52

53

54

55

56

57

58

59

60

61

62

63

64

65

correlated with mean annual precipitation affect genetic distance. The genetic diversity of $C$. dactylon with higher ploidy level was higher than that with lower ploidy level and groups of individuals with higher ploidy level were separated further away by genetic distance from the lower ploidy levels. Understanding the different genetic bases of local adaptation comparatively between latitude and longitude is one of the core findings in the adaptive evolution of plants.

Keywords: Cynodon dactylon; Landscape genetics; Genetic diversity; Longitude; Polyploidy.

\section{Introduction}

Plants will undergo adaptive genomic and phenotypic changes in response to environmental heterogeneity on a spatial scale (Yang et al., 2017; Rellstab et al., 2015). Identification of adaptive genetic diversity and population structure of various populations of different environments is of great significance for improving our understanding of the evolutionary process and exploring the adaptive potential of plants ( $\mathrm{Li}$ et al., 2017). Landscape genetics is helpful for assessing the ability to produce and transmit adaptive genes (Jordan et al., 2017). Genetic differentiation and landscape genetic structure are the results of evolutionary processes including gene migration, random genetic drift and natural selection related to environmental variation due to latitude and longitude. However, gene flow among different populations can effectively prevent genetic difference caused by genetic drift (Schoville et al., 2012; Rundle and Nosil, 2005). Further study of the spatial patterns of genetic diversity is valuable in estimating evolutionary process and predicting the ability of populations to respond to climate change. Studying the genetic structure of more widely distributed plant populations would provide insights into genetic differentiation and evolution. Morphological plasticity and stress tolerances of utilized germplasm should match the environmental characteristics of a specific geographical region (Casler et al., 2004; Boe and Casler, 2005). Population distributions in a large scale could be shaped by regional climate and geographic factors such as latitude and longitude (Peters et al., 2012; Sánchez-gonzález and Lópezmata, 2005). Longitude is correlated with some environmental variables, and environmental factors (like temperature and precipitation) also play important roles in shaping these assemblages along the longitudes. Longitude was the driving factor behind the distribution of some study species, and the distribution of Carex physodes was controlled by longitude (Zhang et al., 2016). Decreasing MAT (mean annual temperature) and MAP (mean annual precipitation), along with 
66 increasing altitude, appear from the east to west along the longitude. Genetic isolation along 67 longitude gradients caused by mountainous environments has been found in other widely 68 distributed Europe-Asian plants (Bartha et al., 2015). Plants in eastern and western Greenland have 69 been genetically different because the Greenlandic ice cap blocks gene flow (Eidesen et al., 2013; 70 Alsos et al., 2009).

71 Bermudagrass (Cynodon dactylon (L.) Pers.) is a genus of the tribe Chlorideae (Poaceae), 72 which inhabits most countries and islands, usually in between about $45^{\circ} \mathrm{N}$ and $45^{\circ} \mathrm{S}$ and penetrates 73 to approximately latitude $53^{\circ} \mathrm{N}$ in Europe (Burton, 1947; Casler et al., 2003). The warm season 74 grass is widely used for turf and pasture because of its drought and heat tolerance and low 75 maintenance requirements (Harlan, 1970; Beard, 1972). C. dactylon is an enormously variable and 76 cosmopolitan warm-season turfgrass used for lawns, parks, and sports fields (Shi et al., 2013), 77 which justifies new and innovative approaches toward evaluating and understanding the genetic relationships among different populations at different longitudes. Some studies have been used to analyze genetic diversity and population structure of bermudagrass because of its efficient dispersal and establishment abilities, rapid population growth, and phenotypic plasticity (Linder et al., 2018; Zheng et al., 2017). Identifying the correlation between simple sequence repeat (SSR) markers and turf-quality-related traits among different bermudagrass populations can efficiently help to select high turf quality for bermudagrass. Different ploidy levels including diploid, triploid, tetraploid, pentaploid and hexaploid have been reported for C. dactylon (Harlan et al., 1970; Wu and Taliaferro, 2009). Polyploidy can improve competitive ability to adapt to new environments, which is vital for the worldwide distribution of grasses (Te Beest et al., 2012; Linder and Barker, 2014). There have been multiple polyploidy events during plant evolution (Wendel, 2015), so evolutionary significance of polyploidy on wild plant populations is being studied. Polyploidy has been the subject of many studies for the genetic and genomic consequences of WGDs (wholegenome duplication) (Soltis et al., 2016).

The lack of genomic information makes genotyping difficult, but molecular markers enhance the study of plant genetic diversity (Govindaraj et al., 2015). SSRs are characterized by high reproducibility, high polymorphism, co-dominant inheritance, and relative abundance across the entire genome (Vasemägi et al., 2005), and are better selective markers for genetic population analysis of some orphan species (Carneiro Vieira et al., 2016; Hodel et al., 2016). EST-SSRs may 
97 (Defaveri et al., 2013). These molecular markers have great potential in genetic diversity and 98 population genetic structure evaluation. Genetic diversity and population structure of $690 C$. dactylon accessions have been analyzed using expressed sequence tag-simple sequence repeats

100

101

102

103

104

105

106

107

108

109

110

111

112

113

114

115

116

117

118

119

120

121

122

123

124

125

126

127 (EST-SSRs), which is a crucial step of studying genetic evolution (Vlachou et al., 1997; Jewell et al., 2010). Although $C$. dactylon has important research value, the understanding of its population genetic structure and geographic variation is limited. Genetic diversity and genetic structure of $C$. dactylon along a latitudinal gradient across China and the relationship between genetic diversity and ploidy levels were also studied in our previous study (Zhang et al., 2019). Sampling includes maximum geographical variation from flooded east to arid west along the longitude to quantify the relative importance of longitude for adaptive genetic divergence of different bermudagrass populations. The genetic diversity of $C$. dactylon along longitude gradients may be correlated to complex geographic conditions and its biological characteristics including perennial growth, windpollination, polyploidy, sexual and asexual reproduction. Different environment factors along longitude gradients can also promote genetic variation and complex genetic structure of $C$. dactylon. Therefore, this study has four objectives (1) quantify population genetic diversity of 249 individuals from 13 populations ranging from different longitudes using EST-SSRs; (2) estimate the spatial population genetic structure and gene flow along longitude; (3) test the relationship between ploidy levels and genetic diversity; (4) compare genetic pattern between longitude and latitude. Studying genetic variation of the wild $C$. dactylon along longitude gradients can promote broadening the genetic resources, understanding the genetic process of adaptation to environmental variation along with longitude and providing some valuable information for the better utilization of wild germplasms of different ploidy levels in breeding.

\section{Materials \& Methods}

Plant materials and DNA extraction

Plant materials consisting of 249 C. dactylon individuals were sampled at 13 different geographic

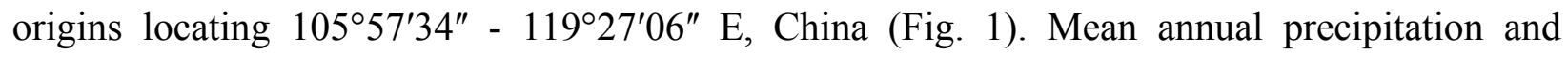
temperature at the collection sites were provided by the China Meteorological Administration (Table 1). Total genomic DNA was extracted using a Zymo Research Plant DNA Extraction Kit (Xinmaijie, Zhengzhou, China) and the quality and concentration of DNA were checked by electrophoresis on $1 \%$ agarose gels. 


\section{EST-SSR amplification}

129 The 20 EST-SSR primer pairs from previous research (Zhang et al., 2019) produced clear and 130 polymorphic bands and were subsequently used to evaluate genetic diversity for this study. $25 \mu \mathrm{L}$ 131 PCR amplifications reaction solution contains $1 \mu \mathrm{L}$ of template DNA, $2.5 \mu \mathrm{L} 10 \times$ PCR buffer, 2 $132 \mu \mathrm{L}$ of $25 \mathrm{mM} \mathrm{MgCl}_{2}, 0.5 \mu \mathrm{L}$ of $10 \mathrm{mM}$ deoxy nucleoside triphos phate (dNTP), $0.5 \mu \mathrm{L}$ each of 133 forward and reverse primers, $0.2 \mu \mathrm{L}$ of Taq DNA polymerase, and $17.8 \mu \mathrm{L}$ of nuclease-free water. 134 The amplifications were performed with the following PCR protocol used in the previous 135 research (Zhang et al., 2019): First 1 cycle of $3 \mathrm{~min}$ at $95^{\circ} \mathrm{C}$, followed by 10 cycles at $95^{\circ} \mathrm{C}, 60^{\circ} \mathrm{C}$ 136 and $72^{\circ} \mathrm{C}$ respectively for $30 \mathrm{~s}$, finally terminating with 1 cycle of 6 min at $72^{\circ} \mathrm{C}$. Next, the samples 137 were subjected to 1 cycle at $95{ }^{\circ} \mathrm{C}$ for $3 \mathrm{~min}$, then 20 cycles of $30 \mathrm{~s}$ at $95^{\circ} \mathrm{C}, 55^{\circ} \mathrm{C}$, and $72^{\circ} \mathrm{C}$ 138 respectively, and finally 1 cycle at $72{ }^{\circ} \mathrm{C}$ for $6 \mathrm{~min}$. PCR amplified fragments labelled with one 139 fluorescent tag (6-FAM (6-carboxyfluorescein) (blue) and HEX (green)) were detected on a 140 3730XL Genetic Analyzer (ABI, USA) with the size standard GS500 LIZ. Capillary 141 electrophoresis analysis was made by using GeneMapper Software Version 4.0 (Applied 142 Biosystems, Foster City, CA, USA).

\section{Analysis of genetic diversity}

144 Genetic diversity for all populations and ploidy levels was calculated using POPGENE V. 1.32 145 Software (Yeh et al., 1997). These indicators included Nei's gene diversity index (He), Shannon 146 diversity index (I) and polymorphic information content (PIC) (Smith et al., 1997; Yeh et al., 147 1999). He was generated according to genetic distance to analysis genetic diversity. I was 148 computed based on the obtained allele frequencies, and PIC reflected the degree of variation of 149 microsatellite DNA. Ploidy level of each sampled individual was determined by using a flow 150 cytometer (Cube8, Partec, Germany) based on the method outlined by Zhang et al. (2020). Linear 151 association between ploidy levels and longitude was investigated under a regression analysis using 152 the software package SPSS13.0 for Windows (SPSS Inc. Chicago, USA) considering correlation 153 coefficient values and significance of variables in the model. All individuals of the same ploidy 154 level were treated as a population to compare the genetic diversity among different ploidy levels. 155 Significant differences in genetic diversity parameters among different populations and ploidy 156 levels were evaluated under a one-way analysis by Duncan's test using SAS 9.3 software (Institute 157 Inc., Cary, NC, USA) (Duncan, 1955). We divided all the individuals into four groups by longitude 
158 from east to west to calculate the genetic diversity parameters for the four groups with four 159 populations within one group as described above.

\section{Analysis of genetic relationship among all populations of $C$. dactylon}

161 Distance matrices of intra-population genetic diversity indicators, environmental distance 162 matrices, genetic distance matrices and geographical distance matrices based on the dataset for 13 163 populations were calculated using GenAlEx 6.1 (Peakall and Smouse, 2006). Mantel correlation 164 tests (Mantel, 1967) between intra-population genetic diversity indexes and environmental factors 165 (temperature and precipitation) were conducted to examine the effects of environments on the 166 intra-population genetic diversity. Mantel correlation coefficient between genetic distances and 167 longitude distances for $C$. dactylon at different spatial scales was also investigated using NTSYS 168 pc version 2.0 (Khan et al., 2002) and the probabilities for the significance were assessed using 169 Bonferroni inequality adjustment. Partial Mantel test was conducted in R (ver. 4.0.5; R Core 170 Development Team 2011) to estimate correlation between genetic distances and geographic 171 distance, while controlling for mean annual precipitation Analyses of molecular variance 172 (AMOVA) and population differentiation index (FST) were estimated using ARLEQUIN v3.5 173 (Excoffier and Lischer, 2010). The significance of FST was determined by random resampling of 174 the genotypic data through 1000 permutations. Principal coordinates (PCoA) analysis of genetic 175 variations at different longitudes was performed using GenAlEx Version 6.1. With the help of 176 clustering in NTSYSpc-v.2.1 software, UPGMA (unweighted pair-group method with arithmetic 177 means) was used for cluster analysis to generate a dendrogram for genetic variation along longitude 178 gradients (Rohlf, 2000).

\section{Population structure analysis}

180 The population structure of the 249 individuals was constructed using a Bayesian clustering 181 method implemented in STRUCTURE 2.3 (Hubisz et al., 2009) as previously described in Zhang 182 et al. (2019). The model-based approach implemented was used to subdivide the individuals into 183 different subgroups. Specifically, twenty independent runs were performed for each simulated 184 value of $\mathrm{K}$ ranging from 2 to 13 . For each run, 10,000 iterations were set as the burn-in time 185 following 100,000 iterations of Markov Chain Monte Carlo (MCMC). Outputs were processed 186 with CLUMPP V1.1.2 (Jakobsson and Rosenberg, 2007) and STRUCTURE barplots were 187 displayed using DISTRUCT 1.1 (Rosenberg, 2004). The best K value was determined from the 
188 modal value of the run with the delta K. Gene flow was calculated using POPGENE V. 1.32 189 Software (Yeh et al., 1997) based on the formula of $\mathrm{Nm}=0.5(1-\mathrm{Gst}) / \mathrm{Gst}$.

190 Mismatch distribution analysis (MDA; Rogers and Harpending, 1992) was used to investigate 191 whether $C$. dactylon had undergone recent population expansion. Goodness-of-fit was tested with 192 the sum of squared deviations (SSD) between observed and expected mismatch distributions 193 (Librado and Rozas, 2009) and Harpending's raggedness index (Harpending, 1994) (HRag), using 1941000 parametric bootstrap replicates. The formula $\mathrm{t}=\tau / 2 \mathrm{u}$ was used to estimate the time since 195 expansion began for the expanding population. The value $\mathrm{u}$ was calculated as $\mathrm{u}=\mu \mathrm{kg}$, where $\mu$ is 196 the substitution rate $\left(6.5 \times 10^{-9}\right.$ synonymous substitutions per synonymous site per year (Gaut et $197 \mathrm{al} ., 1996)), \mathrm{k}$ is the average sequence length used for analysis (105 bp) and $\mathrm{g}$ is the generation time 198 in years (1 year was used as an approximation for $\mathrm{g}$ according to age of first reproduction of $C$. 199 dactylon). Fu's FS (Fu, 1997) and Tajima's D (Tajima, 1989) neutrality test were used to infer 200 demographic history of each population. Statistical significance was estimated by performing 1000 201 random permutations. Demographic analyses were performed in ARLEQUIN.

202

203 Results

204 Genetic diversity and differentiation along longitude gradient

205 The genetic diversity parameters including the PIC value, He and I were calculated for EST-SSR 206 markers in 13 populations (Table 2). The PIC values ranged from a high of 0.68 and a low of 0.40. 207 Highest He value of 0.19 and lowest of 0.06 were calculated. The value of I ranged from 0.11 to 2080.34 respectively for EST-SSR markers. Non-significant difference in genetic diversity parameters 209 among groups (group 1 consisted of populations 1-3; group 2 consisted of populations 4-6; group 2103 consisted of populations 7-9; group 4 consisted of populations 10-13) was observed along 211 longitude gradients (He among populations: $\mathrm{F}=0.027, P=0.974)$. However, populations $4,5,6$ 212 and 8 at mid-longitude and populations 1, 12,13 at lowest and highest longitude had higher genetic 213 diversity than other populations according to I and He (Fig. 2). In general, there was also no 214 significant correlation $(P>0.05)$ between intra-population genetic diversity and climate (mean 215 annual temperature and precipitation), suggesting that temperature and precipitation showed little 216 influence on intra-population genetic diversity along longitudes.

217 AMOVA results indicated that $38.23 \%$ of the genetic variation was attributed to difference 218 among populations. About $61.77 \%$ of the genetic variation showed within population, which 
219 accounted for a greater part of the whole genetic variation (Table 3).Mantel's test revealed 220 significantly positive correlation between genetic distance and longitudinal distance $(\mathrm{r}=0.276, P$ $221=0.022)$. Environmental measures along longitude gradients (geographical distance $(\mathrm{r}=0.438, P$ $222=0.001)$; mean annual precipitation $(\mathrm{r}=0.305, P=0.033))$ were correlated with genetic distance, 223 while mean annual temperature was not $(\mathrm{r}=0.006, P=0.418)$. However, a partial Mantel test 224 accounting for mean annual precipitation was used to estimate that genetic distance was not 225 independently correlated with geographic distance $(P=0.146)$. Gene flow $(\mathrm{Nm})$ among these $C$. 226 dactylon populations along longitude gradients was $0.7701(<1)$, which mainly reflected low 227 communication frequency of gene among populations.

228 Genetic separation by UPGMA dendrogram and principal coordinate analysis 229 A UPGMA dendrogram dependent on Nei's genetic distance showed that 13 different populations 230 were grouped into three distinct clusters (Fig. 3). The first cluster consisted of populations from 231 Lianyungang and Tancheng that located at high-longitude in the east of China near the Yellow 232 Ocean. Most populations along longitude gradient assigned to the second cluster, so a certain 233 degree of kinship was identified among populations of $C$. dactylon located at different regions 234 along longitude gradient. Populations 7, 9, 10 clustered together and population 3 was close to 235 population 5 . The third mixture cluster contained plants coming exclusively from interval locations 236 along the longitude, such as Shanxian (4), Zhengzhou (6), Sanmenxia (8), and Baoji (12). In 237 addition, each of four populations in the mixture cluster had higher intra-population genetic 238 diversity. The Principal coordinate analysis (PCoA) (Fig. 4) revealed a similar pattern as inferred 239 with UPGMA dendrogram. The first, second and third principal coordinates respectively explained $24031.57 \%, 17.78 \%$ and $11.90 \%$, altogether $61.25 \%$ of the variability. At axis one, 13 populations 241 could be divided into two parts with one of cluster 2 and others of clusters 1, 3. At axis two, cluster 2421 consisting of populations 1 and 2 could be clearly separated from cluster 3 . Additionally, 243 populations of cluster 1 were clearly far from the other populations. Populations 3, 5, 7, 9 and 10 244 clustered together in the cluster 2. Populations 4, 6, 8 and 12 with relatively higher genetic diversity 245 formed the cluster 3.

\section{Population genetic structure of $\boldsymbol{C}$. dactylon}

247 Bayesian analysis of the population structure of $C$. dactylon was used to conduct separate 248 calculation from $\mathrm{K}=2$ to $\mathrm{K}=20$. The results clearly demonstrated that the appropriate $\mathrm{K}$ values 249 were obtained when the 13 populations were subdivided into 4 or 8 groups (Fig. S1). The results 
250 of 13 populations from $\mathrm{K}=2-13$ strongly indicated different clusters in populations of $C$. dactylon 251 (Fig. 5; Fig. S2). When $\mathrm{K}=4$, population 1 and 2 clustered together (blue) and the cluster with 252 green consisted of populations 4, 6, 8, 12. Populations 5, 7, 10, 13 were differentiated from 253 populations $3,9,11$ compared to $\mathrm{K}=3$. And when $\mathrm{K}=8$, one group included populations $3,5,7,9$, 254 10, and another group consisted of the populations 8 and 12. Each of the other six groups consisted 255 of only one population respectively, which indicated a rich genetic differentiation along longitude 256 gradients. Admixture among populations of medium longitude (populations 5, 6, 8, 9) could be 257 observed from the structure of $C$. dactylon populations $(\mathrm{K}=2$ to 13$)$, the clustering of populations 258 at low and high longitude were relatively stable except for the populations 1, 12, 13.

\section{Mismatch analysis and neutral test of $\boldsymbol{C}$. dactylon}

260 The mismatch distribution for each population of C. dactylon (Table 4) suggested populations 126111,13 possibly underwent recent population expansion. The result was also proved by significantly 262 negative values of Fu's FS among the 13 populations of $C$. dactylon. Significant SSD values and 263 non-significantly positive Tajima's D values of the population 12 might suggest relatively stable 264 population size in Baoji. In addition, the demographic expansion time of each population was 265 calculated based on the value of $\tau$.

\section{Genetic variation and differentiation among different ploidy levels}

267 Genetic diversity (He and I) results of $C$. dactylon with five ploidy levels showed that triploid had 268 significantly lower genetic diversity than pentaploid $(P=0.019$ for He; $P=0.008$ for I) and 269 hexaploid $(P=0.049$ for He; $P=0.020$ for I) (Table S1). The genetic diversity of the C. dactylon 270 individuals with higher ploidy level was significantly higher than that of individuals with lower 271 ploidy level except for diploid. Significant genetic diversity exists among different ploidy level, 272 but there is no significant difference in genetic diversity between pentaploid and hexaploid based 273 on trend lines of PIC $(P>0.05)$. Diploid and triploid respectively had significantly lower genetic 274 diversity than other polyploidy. All the individuals of $C$. dactylon at different ploidy levels fell 275 into three major clusters based on UPGMA. The first and second clusters contained diploid and 276 triploid individuals, respectively. Tetraploid, pentaploid, and hexaploid individuals formed the 277 third cluster (Fig. 6). The genetic distance between two groups among different ploidy levels 278 increased with the increase of ploidy level. In addition, there was no obvious growth trend of the 279 distribution of ploidy levels, and regression analysis indicated that there was no significant linear 280 association between ploidy level and longitude ( $\mathrm{r}=0.071 ; P>0.05-$ Fig. 7$)$. 


\section{Discussion}

\section{Genetic diversity and structure among populations along longitude gradients}

284

285

286

287

288

289

290

291

292

293

294

295

296

297

298

299

300

301

302

303

304

305

306

307

308

309

310

311

Identifying relative roles of spatial and environmental factors in shaping patterns of population genetic differentiation is of interest for understanding landscape genetics. Each of 13 populations of $C$. dactylon along longitude gradients had a remarkable genetic variation within population based on the study. Genetic diversity can be improved by sexual propagation, and clonal propagation by rhizome and stolon can promote stable inheritance not being easily affected by genetic drift (Loveless and Hamrick, 1984). Intra-population genetic diversity had no obvious linear relationship with longitude in this study. In addition, mean annual temperature and precipitation at different longitudes had no significant influence on the intra-population genetic diversity. However, according to our previously published paper, higher within-population genetic diversity appeared at lower latitude with higher temperature $\left(>25^{\circ} \mathrm{C}\right)$, while relatively low temperature at higher latitude might have little effect on the intra-population genetic diversity (Zhang et al., 2019). So higher temperature $\left(>25^{\circ} \mathrm{C}\right)$ may be associated with higher genetic variation of $C$. dactylon. From sampling regions, there was a little higher genetic diversity of populations at mid-longitudes $(4,5,6,8)$ than other populations at low- and high-longitudes, because outcrossing and self-incompatibility of $C$. dactylon could produce low communication among different populations of the east-west transitional locations. Genetic differences among distant geographical sites with unique alleles can increase genetic diversity (Brochmann et al., 2003; Westergaard et al., 2011; Parducci et al., 2012; Eidesen et al., 2013).

Landscape heterogeneity may lead to the formation of local adaptive populations, and different genotypes may be selected to adapt to different environments (Felsenstein, 1976; Rieseberg and Willis, 2007; Anderson et al., 2011). Environmental distance matrices were also calculated to estimate the influences of environmental distance matrices (IBE) on the genetic distance. No significant correlation was observed between genetic distance and geographic distance after controlling the effect of mean annual precipitation, which might be due to a correlation between geographic distance and mean annual precipitation. P. arundinacea (Phalaris) also exhibits a certain broad-scale population genetic structure in east-to-west gradients (Perdereau et al., 2017). The adaptive differentiation among populations is influenced by the natural selection of heterogeneous landscape and gene flow (Dionne et al., 2008; Poelchau and Hamrick, 2012). Low 
312 east-to-west inter-population gene flow $(\mathrm{Nm}=0.7701)$ indicated that there was little adaptive 313 selective pressure mediated evolutionary dynamics among different populations along longitude 314 gradients (Casler et al., 2007). In addition, these factors to hinder further communication among 315 populations include the transmission mechanism of pollen and seeds of species and the barrier 316 317 populations at different longitudes exhibiting significant IBD, and mountains in the Henan-Shanxi 318 region may hinder further genetic communication among populations as natural barriers. Alpine 319 plants from several mountain ranges in Europe usually have a strong patterns of longitudinal 320 differentiation (Ronikier et al., 2008; 2012). Geographical isolation along an ecological gradient

321

322 323 324 325 326 327 328 329 330

331 332 333 334 335 336 337 338 339 340 or environmental isolation can lead to strong genetic differentiation for widespread plants (Hoskin et al., 2005).

The result of AMOVA indicated $61.77 \%$ of the genetic variation was attributed to differences within populations and FST was 0.3823. Higher FST along with increasing distance along longitude than latitude gradients may indicate local genetic differentiation among populations along longitude gradients (Edillo et al., 2009). Both spatial and environmental factors interweave in the formation of population differentiation pattern. In our case, low gene flow among neighboring populations may show the isolation-by-distance pattern among two neighboring populations. Several reproductive barriers in different environments within the same geographical area can block gene flow (Lowry, 2012; Fishman et al., 2013). Interestingly, some populations separated by $200 \mathrm{~km}$ in distance are close in genetic distance. A probable explanation is that human-mediated introduction allow contact among these populations. The mismatch distribution test and neutrality test both indicated expansion within population along longitude gradients, with an estimated time around 12.5 Ma (under the demographic expansion model), which may be related to forests shrink and grasslands spread during Miocene time. The dramatic expansion of C4 grasslands in India is a part of increasing tropical C4 savannah vegetation worldwide in the late Miocene, which has been variously ascribed to uplift of the Tibetan plateau (Polissar et al., 2015). In contrast, the population in Baoji with non-significant SSD and HRag values was interpreted as reflecting past demographic stability.

The low number of admixed genotypes at mid-longitude can be explained by the geographical distribution of the collection sites. Natural or human-mediated transmission may have increased genetic diversity and affected the genetic structure of several grass species (Balfourier et al., 2000; 
343 McGrath et al., 2007; Petit et al., 2003; Taberlet et al., 1998). Hybridization at population

344 boundaries and gene migration appear to promote homogenization. Populations at low and high-

345 longitude may evolve much earlier than populations from sites of mid-longitude based on the

346 result. Therefore, populations of $C$. dactylon at mid-longitude may evolve from complex

347 introgressions between populations at low and high-longitude with close genetic affiliation.

348 Historic changes in landscape configuration, spatial isolation and related gene flow changes may

349 gradually lead to intraspecific genetic variation between eastern and western populations of $C$.

350 dactylon in different geographical areas. The admixture among populations determines their 351 potential to adapt to new environmental conditions (Lee, 2002).

\section{Relationship between ploidy levels and genetic diversity}

353 The higher values of He, I and PIC were observed in populations with pentaploid and hexaploid 354 than triploid. Polyploid retains most of the population's gene pool in the form of fixed 355 heterozygosity (Brochmann et al., 2004). Hybridization of polyploid progeny from different 356 parents of the same species can increase the genetic diversity. Multiple introductions from different

357

358

359

360

361

362

363

364

365

366

367

368

369

370

371

372 Comparison of genetic pattern between longitude and latitude

origins and recombination between different genomes led to genetic mixture. Moreover, groups of individuals with the same ploidy level were separated by genetic distance along with the increasing ploidy levels. The higher genetic distance between two different ploidy levels along with the increasing ploidy levels was observed in the study, which indicated that each chromosome replication process might gradually increase the genetic dissimilarity. Diploid plants can participate in the formation of many polyploid (Ramsey and Schemske, 2002; Otto, 2007), and polyploid are often separated from their progenitors to produce new genotypes (Čertner et al., 2017; Alsayied et al., 2015; Sweigart et al., 2008). Different chromosome numbers could lead to reproductive segregation or sterility, which limited gene flow between hybrids and their parents (Tate et al., 2005). Polyploidy not only produce direct genetic redundancy, but also promote emergence of new gene functions and drive diversification and evolution (Alix et al., 2017). The hybrid genome composition of two related heterotetraploid species was analyzed using molecular cytogenetics to elucidate the role of heteropolyploid in the realization of Hordeum diversity (Cuadrado et al., 2017). From the facts above, polyploidization can lead to rich genetic variation and diversification for probable speciation of $C$. dactylon. 
373 No significant difference exists in genetic diversity parameters within-population along longitude 374 gradients, while higher within-population genetic diversity appeares at low latitude with higher 375 temperature along latitudinal gradients $\left(>25^{\circ} \mathrm{C}\right.$ ) (Zhang et al., 2019). The result showed higher 376 temperature might promote higher within-population genetic variation of $C$. dactylon. The barrier 377 of hybridization of rice mainly focused on the environmental variation, just as temperature 378 influenced cellularization of the endosperm to promote hybrid (Folsom et al., 2014). Higher 379 temperatures may have affected the genetic similarity of Culex pipiens populations sampled early 380 and later in the breeding season (Edillo et al., 2009).

381 A relatively low gene flow $(\mathrm{Nm}=0.7701)$ means a rich genetic differentiation along longitude 382 gradients $(\mathrm{Nm}<1)$ (Wright, 1965). In our previous study on the genetic diversity and genetic 383 structure of $C$. dactylon along a latitudinal gradient, low genetic differentiation and notable 384 385 admixture structure existed among populations along latitudes (Zhang et al., 2019). Low genetic differentiation caused by different latitudes may be attributed to the wind-pollination outcrossing system and vegetative materials through human activities, which indicated that the latitude interval could not be an obstacle to genetic exchange. In addition, stronger admixture could be observed 388 along with the latitude in another study (Zhang et al., 2019) than that along with longitude in this study, which indicated relatively lower gene flow among populations of $C$. dactylon occurred 390 along the longitude gradients. North-south direction gene flow has existed between the eastern Lemus chinense populations and the western ones (Long et al., 2019). The eastern Eurasian populations of some species with global distribution pattern are a little different from-the western Eurasian populations, which occurs between late Miocene and Pleistocene (Tabata et al., 2018; Hardouin et al., 2015; Rodrigues et al., 2014). East Asia was less extensively glaciated and had a relatively mild glacial climate. The Qinghai-Tibetan Plateau uplifted rapidly in Pleistocene and the Asian summer monsoon intensified, so the formation of the inland arid belt of Eurasia resulted in long-term ecological isolation (Clark and Mix, 2002; López-Pujol et al., 2011). A probable 398 explanation is that the genetic differentiation along longitude gradients was little and the gene flow was frequent before the uplift of Tibet Plateau, but the situation reversed after that because populations were ecologically isolated. Therefore making a comparison between latitude and longitude, a stronger gene flow from the north-south than east-west direction is characteristic of 402 genetic structure of $C$. dactylon in China. Distinct genetic divergence of $C$. dactylon presented 403 between the lower and the higher ploidy level along both longitude and latitude gradients. In 
404 addition, widespread polyploidization may cause significantly increasing genetic diversity with 405 the ploidy level.

406

407 Conclusions

408 A large-scale population genetic survey of genetic diversity of $C$. dactylon has been conducted to 409 evaluate genetic variation and population structure along a longitude gradient. Landscape 410 heterogeneity and geographical isolation along several mountain ranges can lead to formation of 411 locally adapted populations with reduced gene flow between habitats. Geographic distance 412 correlated with precipitation may influenced genetic diversity among populations along longitude 413 gradients. A higher level of genetic differentiation among populations of C. dactylon along 414 longitude gradients than those along latitudinal gradients indicated a stronger gene flow from the 415 north-south than east-west direction. Decreased genetic diversity is estimated for individuals with 416 lower ploidy level compared to higher ploidy level, and relatively rich genetic differentiation exists 417 among different ploidy levels. Identifying genetic diversity along longitude gradients in contrast 418 with latitudinal gradients provides important genetic information and improves the ability to 419 protect biodiversity.

420

421 ADDITIONAL INFORMATION AND DECLARATIONS

\section{Funding}

423 This work was supported by National Natural Science Foundation of China (no. 31702165).

\section{Competing interests}

425 The authors declare that they have no competing interests.

\section{Authors Contributions}

427 - Jing-Xue Zhang conceived and designed the experiments, performed the experiments, analyzed 428 the data, prepared figures and/or tables, authored or reviewed drafts of the paper, and approved 429 the final draft.

430 - Xue-Bing Yan and Yu-Xia Guo conceived and designed the experiments, authored or reviewed 431 drafts of the paper, and approved the final draft.

432 - Miao-Li Wang, Biao-Ji Fan, Zhi-Peng Guo, Yong-Zhuo Guan, Gen Qu performed the 433 experiments and approved the final draft. Chuan-Jie Zhang checked linguistic accuracy and 434 approved the final draft. 
437

438

439

440

441

442

443

444

445

446

447

448

449

450

451

452

453

454

455

456

457

458

459

460

461

462

463

464

465

466

467

468

469

470

471

472

\section{References}

Alix K, Gérard PR, Schwarzacher T, Heslop-Harrison JS. 2017. Polyploidy and interspecific hybridization: partners for adaptation, speciation and evolution in plants. Annals of Botany 120(2):183-194.

Alsayied N, Fernández JA, Schwarzacher T, Heslop-Harrison JS. 2015. Diversity and relationships of Crocus sativus and its relatives analysed by inter-retroelement amplified polymorphism (IRAP). Annals of Botany 116:359-368.

Alsos IG, Torbjorn, A, Normand S, Brochmann C. 2009. Past and future range shifts and loss of diversity in dwarf willow (Salix herbacea L.) inferred from genetics, fossils and modelling. Global Ecology and Biogeography 18:223-239.

Anderson JT, Willis JH, Mitchell-Olds T. 2011. Evolutionary genetics of plant adaptation. Trends in Genetics 27:258-266.

Balfourier F, Imbert C, Charmet G. 2000. Evidence for phylogeographic structure in Lolium species related to the spread of agriculture in Europe. A cpDNA study. Theoretical and Applied Genetics 101:131-138.

Bartha L, Sramkó G., Volkova PA, Surina B, Ivanov AL, Banciu HL. 2015. Patterns of plastid DNA differentiation in Erythronium (Liliaceae) are consistent with allopatric lineage divergence in Europe across longitude and latitude. Plant Systematics and Evolution 301(6):1747-1758.

Beard JB. 1972. Turfgrass: Science and Culture. Prentice-Hall, Englewood Cliffs.

Boe A, Casler MD. 2005. Hierarchical analysis of switchgrass morphology. Crop Science. 45:2465-2472.

Brochmann C, Brysting AK, Alsos IG, Borgen L, Grundt HH, Scheen AC, Elven R. 2004. Polyploidy in arctic plants. Biological Journal of the Linnean Society 82:521-536.

Brochmann C, Gabrielsen TM, Nordal I, Landvik JY, Elven R. 2003. Glacial survival or tabula rasa? The history of North Atlantic biota revisited. Taxon 52:417-450.

Burton GW. 1947. Breeding bermudagrass for the Southeastern United States. Agronomy Journal 39:8.

Carneiro Vieira ML, Santini L, Diniz AL, de Freitas Munhoz C. 2016. Microsatellite markers: what they mean and why they are so useful. Genetics and Molecular Biology 39:312-28.

Casler MD, Duncan RR. 2003. Turfgrass biology, genetics and breeding. John Wiley \& Sons.

Casler MD, Vogel KP, Taliferro CM, Wynia RL. 2004. Latitudinal adaptation of switchgrass populations. Crop Science 44:293-303.

Casler MD, Vogel KP, Taliaferro CM, Ehlke NJ, Berdahl JD, Brummer EC, Kallenbach RL, West CP, Mitchell RB. 2007. Latitudinal and longitudinal adaptation of switchgrass populations. Crop Science 47(6):22492260.

Čertner M, Fenclová E, Kúr P, Koláŕ F, Koutecký P, Krahulcová A, Suda J. 2017. Evolutionary dynamics of mixed-ploidy populations in an annual herb: dispersal, local persistence and recurrent origins of 
473

474

475

476

477

478

479

480

481

482

483

484

485

486

487

488

489

490

491

492

493

494

495

496

497

498

499

500

501

502

503

504

505

506

507

polyploids. Annals of Botany 120:303-315.

Clark PU, Mix AC. 2002. Ice sheets and sea level of the Last Glacial Maximum. Quaternary Science Reviews 21:1-7.

Cuadrado A, de Bustos A, Jouve N. 2017. On the allopolyploid origin and genome structure of the closely related species Hordeum secalinum and Hordeum capense inferred by molecular karyotyping. Annals of Botany $120: 245-255$.

Defaveri J, Viitaniemi H, Leder E, Merila J. 2013. Characterizing genic and nongenic molecular markers: Comparison of microsatellites and SNPs. Molecular Ecology Resources 13:377-392.

Dionne M, Caron F, Dodson JJ, Bernatchez L. 2008. Landscape genetics and hierarchical genetic structure in Atlantic salmon: the interaction of gene flow and local adaptation. Molecular Ecology 17(10):2382-96.

Duncan DB. 1955. Multiple Range and Multiple F Tests. Biometrics 11:1-42.

Edillo F, Kiszewski A, Manjourides J, Pagano M, Hutchinson M, Kyle A, Arias J, Gaines DN, Lampman R, Novak R, Foppa IM, Lubelczyk C, Smith R, Moncayo A, Spielman A. 2009). Effects of latitude and longitude on the population structure of Culex pipiens sl, vectors of West Nile virus in North America. American Journal of Tropical Medicine \& Hygiene 81(5):842-848.

Eidesen PB, Ehrich D, Bakkestuen V, Alsos IG, Gilg O, Taberlet P, Brochmann C. 2013. Genetic roadmap of the Arctic: Plant dispersal highways, traffic barriers and capitals of diversity. New Phytologist 200:898-910.

Excoffier L, Lischer HEL. 2010. Arlequin suite ver 3.5: a new series of programs to perform population genetics analyses under Linux and windows. Molecular Ecology Resources 10:564-567.

Felsenstein J. 1976. The theoretical population genetics of variable selection and migration. Annual Review of Genetics 10:253-280.

Fishman L, Stathos A, Beardsley PM, Williams CF, Hill JP. 2013. Chromosomal rearrangements and the genetics of reproductive barriers in Mimulus (monkey flowers). Evolution 67:2547-2560.

Folsom JJ, Begcy K, Hao X, Wang D, Walia H. 2014. Rice fertilization-independent endosperm1 regulates seed size under heat stress by controlling early endosperm development. Plant Physiology 165(1):238-248.

Fu YX. 1997. Statistical tests of neutrality of mutations against population growth, hitchhiking and background selection. Genetics 147(2): 915-925.

Gaut BS, Morton BR, McCaig BC, Clegg MT. 1996. Substitution rate comparisons between grasses and palms: synonymous rate differences at the nuclear gene Adh parallel rate differences at the plastid gene rbcL. Proceedings National Academy of Sciences of the United States of America 93:10274-10279.

Govindaraj M, Vetriventhan M, Srinivasan M. 2015. Importance of genetic diversity assessment in crop plants and its recent advances: an overview of its analytical perspectives. Genetic Research International 215:14.

Hardouin EA, Orth A, Teschke M, Darvish J, Tautz D, Bonhomme F. 2015. Eurasian house mouse (Mus musculus L.) differentiation at microsatellite loci identifies the Iranian plateau as a phylogeographic hotspot. BMC Evolutionary Biology 15:26.

Peer) reviewing PDF | (2020:11:55742:3:1:REVIEW 27 May 2021) 
508 Harlan JR. 1970. Cynodon species and their value for grazing or hay. Herbage Abstracts 40: 233-238.

509 Harlan JR, de Wet JMJ, Rawal KM, Felder MR, Richardson WL. 1970. Cytogenetic studies in Cynodon L.C.

510 Rich. (Gramineae). Crop Science 10:288-291.

511 Harpending HC. 1994. Signature of ancient population growth in a low-resolution mitochondrial DNA mismatch 512 distribution. Human Biology 66(4): 591-600.

513 Hodel RG, Segovia-Salcedo MC, Landis JB, Crowl AA, Sun M, Liu X, Gitzendanner MA, Douglas NA, 514 Germain-Aubrey C, Chen SC, Soltis DE, Soltis PS. 2016. The report of my death was an exaggeration: a 515 review for researchers using microsatellites in the 21st century. Applications in Plant Sciences 4:17.

516 Hoskin CJ, Higgie M, McDonald KR, Moritz C. 2005. Reinforcement drives rapid allopatric speciation. Nature $517 \quad 437: 1353-1356$.

518 Hubisz MJ, Falush D, Stephens M, Pritchard JK. 2009. Inferring weak population structure with the assistance 519 of sample group information. Molecular Ecology Resources 9:1322-1332.

520 Jakobsson M, Rosenberg NA. 2007. CLUMPP: a cluster matching and permutation program for dealing with 521 label switching and multimodality in analysis of population structure. Bioinformatics 23:1801-1806.

522 Jewell MC, Frere CH, Prentis PJ, Lambrides CJ, Godwin ID. 2010. Characterisation and multiplexing of EST523 SSR primers in Cynodon (Poaceae) species. American Journal of Botany 97:e99-e101.

524 Jordan R, Hoffmann AA, Dillon SK, Prober SM. 2017. Evidence of genomic adaptation to climate in Eucalyptus microcarpa: implications for adaptive potential to projected climate change. Molecular Ecology 26(21):6002-6020.

Khan A, Nawaz M, Khan S, Steele R. 2002. Detection and characterization of erythromycin-resistant methylase genes in Gram-positive bacteria isolated from poultry litter. Applied Microbiology and Biotechnology 59:377-381.

530 Lee CE. 2002. Evolutionary genetics of invasive species. Trends in Ecology and Evolution 17: 386-391.

531 Li Y, Zhang XX, Mao RL, Yang J, Miao CY, Li Z, Qiu XY. 2017. Ten years of landscape genomics: challenges and opportunities. Front Plant Science 8:2136.

533 Librado P, Rozas J. 2009. DnaSP v5: a software for comprehensive analysis of DNA polymorphism data. Bioinformatics 25(11): 1451-1452.

Linder HP, Barker NP. 2014. Does polyploidy facilitate long-distance dispersal? Botany-Botanique 113:11751183.

Linder HP, Lehmann CER, Archibald S,Osborne CP, Richardson DM. 2018. Global grass (Poaceae) success underpinned by traits facilitating colonization, persistence and habitat transformation. Biological Reviews 93:1125-1144.

540 Long X, Weng Y, Liu S, Hao Z, Sheng Y, Guan L, Shi J, Chen J. 2019. Genetic diversity and differentiation of relict plant Liriodendron populations based on 29 novel EST-SSR markers. Forests 10(4):334.

542 López-Pujol J, Zhang FM, Sun HQ, Ying TS, Ge S. 2011. Centres of plant endemism in China: Places for $543 \quad$ survival or for speciation? Journal of Biogeography 38:1267-1280. 
544 Loveless MD, Hamrick JL. 1984. Ecological determinants of genetic structure in plant populations. Annual

545 Review of Ecology Evolution and Systematics 15: 65-95.

546 Lowry DB. 2012. Ecotypes and the controversy over stages in the formation of new species. Biological Journal 547 of the Linnean Society 106:241-257.

548 Mantel N. 1967. The detection of disease clustering and a generalized regression approach. Cancer Research 549 27(2): 209-220.

550 McGrath S, Hodkinson TR, Barth S. 2007. Extremely high cytoplasmic diversity in natural and breeding 551 populations of Lolium (Poaceae). Heredity 9:531-544.

552 Otto SP. 2007. The evolutionary consequences of polyploidy. Cell 131(3):452-462.

553 Parducci L, Jørgensen T, Tollefsrud MM, Elverland E, Alm T, Fontana SL, Alsos IG, Willerslev E. 2012. 554 Glacial survival of boreal trees in northern Scandinavia. Science 335(6072):1083-1086.

555 Peakall R, Smouse P. 2006. GENALEX 6: Genetic analysis in Excel. Population genetic software for teaching 556 and research. Molecular Ecology Notes 6:288-295.

557

Perdereau A, Klaas M, Barth S, Hodkinson TR. 2017. Plastid genome sequencing reveals biogeographical

558 structure and extensive population genetic variation in wild populations of Phalaris arundinacea L. in

559 north-western Europe. Gcb Bioenergy 9(1):46-56.

560

Peters DPC, Yao J, Sala OE, Anderson JP. 2012. Directional climate change and potential reversal of 561 desertification in arid and semiarid ecosystems. Global Change Biology 18:151-63.

562

Petit RJ, Aguinagalde I, de Beaulieu JL, Bittkau C, Brewer S, Cheddadi R, Ennos R, Fineschi S, Grivet D,

563

564

565

566

567

568

569

570

571

572

573

574

575

576

577

578 Lascoux M, Mohanty A, Mu G, Demesure-musch B, Palme A, Martı J, Rendell S, Vendramin G. 2003. Glacial refugia: Hotspots but not melting pots of genetic diversity. Science 300:1563-1565.

Poelchau MF, Hamrick JL. 2012. Differential effects of landscape-level environmental features on genetic structure in three codistributed tree species in Central America. Molecular Ecology 21(20):4970-4982.

Polissar PJ, Uno KT, Phelps SR, Pensky JL. 2015. The role of hydroclimate in the late-Miocene expansion of C 4 grasses in India. AGUFM 2015: PP21B-2245.

Ramsey J, Schemske DW. 2007. Neopolyploidy in flowering plants. Annual Review of Ecology Evolution and Systematics 2002(33):589-639.

Rellstab C, Gugerli F, Eckert AJ, Hancock AM, Holderegger R. 2015. A practical guide to environmental association analysis in landscape genomics. Molecular Ecology 24(17):4348-4370.

Rogers AR, Harpending HC. 1992. Population growth makes waves in the distribution of pairwise genetic differences. Molecular Biology and Evolution 9: 552-569.

Ronikier M, Cieślak E, Korbecka G. 2008. High genetic differentiation in the alpine plant Campanula alpina Jacq. (Campanulaceae): evidence for glacial survival in several Carpathian regions and long-term isolation between the Carpathians and the Alps. Molecular Ecology 17:1763-1775.

Ronikier M, Schneeweiss GM, Schönswetter P. 2012. The extreme disjunction between Beringia and Europe in 
579

580

581

582

583

584

585

586

587

588

589

590

591

592

593

594

595

596

597

598

599

600

601

602

603

604

605

606

607

608

609

610

611

612

613

Ranunculus glacialis s.l. (Ranunculaceae) does not coincide with the deepest genetic split—a story of the importance of temperate mountain ranges in arctic-alpine phylogeography. Molecular Ecology 21:55615578.

Rieseberg LH, Willis JH. 2007. Plant speciation. Science 317:910-914.

Rodrigues ASB, Silva SE, Marabuto E, Silva DN, Wilson MR, Thompson V, Yurtsever S, Halkka A, Borges PAV, Quartau JA, Paulo OS, Seabra SG. 2014. New mitochondrial and nuclear evidences support recent demographic expansion and an atypical phylogeographic pattern in the spittlebug Philaenus spumarius (Hemiptera, Aphrophoridae). PLoS ONE 9:e98375.

Rohlf FJ, Rohlf FJ, Rohlf F, Rohlf FJ. 2000. NTSYS-pc numerical taxonomy and multivariate analysis system version 2.1. Owner manual.

Rosenberg NA. 2004. DISTRUCT: a program for the graphical display of population structure. Molecular Ecology Notes 4:137-138.

Rundle HD, Nosil P. 2005. Ecological speciation. Ecology Letters 8(3):336-352.

Sánchez-gonzález A, López-mata L. 2005. Plant species richness and diversity along an altitudinal gradient in the Sierra Nevada, Mexico. Divers Distribution 11:567-75.

Schoville S, Bonin A, Francois O, Lobreaux S, Melodelima C, Manel S. 2012. Adaptive genetic variation on the landscape: methods and cases. Annual Review of Ecology Evolution and Systematics 43:23-43.

Shi H, Ye T, Chan Z. 2013. Exogenous application of hydrogen sulfide donor sodium hydrosulfide enhanced multiple abiotic stress tolerance in bermuda grass (Cynodon dactylon (L). Pers.). Plant Physiology Biochemistry 71: 226-234.

Smith JSC, Chin ECL, Shu H, Smith OS, Wall SJ, Senior ML, Mitchell SE, Kresovich S, Ziegle J. 1997. An evaluation of the utility of SSR loci as molecular markers in maize (Zea mays L.): comparisons with data from RFLPs and pedigree. Theoretical and Applied Genetics 95:163-173.

Soltis DE, Visger CJ, Marchant DB, Soltis PS. 2016. Polyploidy: pitfalls and paths to a paradigm. American Journal of Botany 103:1146-1166.

Sweigart AL, Martin NH, Willis JH. 2008. Patterns of nucleotide variation and reproductive isolation between a Mimulus allotetraploid and its progenitor species. Molecular Ecology 17:2089-2100.

Tabata R, Kawaguchi F, Sasazaki S, Yamamoto Y, Bakhtin M, Kazymbet P, Meldevekob A, Suleimenov MZ, Nishibori M, Mannen H. 2018. The Eurasian Steppe is an important goat propagation route: A phylogeographic analysis using mitochondrial DNA and Y-chromosome sequences of Kazakhstani goats. Animal Science Journal 90:317-322.

Taberlet P, Fumagalli L, Wust-Saucy AG, Cosson JF. 1998. Comparative phylogeography and postglacial colonization routes in Europe. Molecular Ecology 7:453-464.

Tajima F. 1989. Statistical-method for testing the neutral mutation hypothesis by DNA polymorphism. Genetics 123(3): 585-595.

PeerJ reviewing PDF | (2020:11:55742:3:1:REVIEW 27 May 2021) 
614 Tate JA, Soltis DE, Soltis PS. 2005. CHAPTER 7-Polyploidy in Plants. The Evolution of the Genome 2005:371615426.

616 Te Beest M, Le Roux JJ, Richardson DM, Brysting AK, Suda J, Kubešová M, Pyšek P. 2012. The more the 617 better? The role of polyploidy in facilitating plant invasions. Annals of Botany 109:19-45.

618 Vasemägi A, Nilsson J, Primmer CR. 2005. Expressed sequence tag-linked microsatellites as a source of gene-

619

620

621

622

623

624

625

626

627

628

629

630

631

632

633

634

635

636

637

638

639

640

641

642

643

644

645

646

647

648 associated polymorphisms for detecting signatures of divergent selection in atlantic salmon (Salmo salar L.). Molecular Biology and Evolution 22:1067-1076.

Vlachou D, Konsolaki M, Tolias PP, Kafatos FC, Komitopoulou K. 1997. Conserved synteny, amplification and tissue specificity but sequence divergence and altered temporal regulation. Genetics 147:1829-1842.

Wendel JF. 2015. The wondrous cycles of polyploidy in plants. American Journal of Botany 102:1753-1756.

Westergaard KB, Alsos IG, Popp M, Engelskjøn T, Flatberg KI, Brochmann C. 2011. Glacial survival may matter after all: Nunatak signatures in the rare European populations of two west-arctic species. Molecular Ecology 20:376-393.

Wright S. 1965. The interpretation of population structure by F-Statistics with special regard to systems of mating. Evolution 19:395.

$\mathrm{Wu}$ Y, Taliaferro CM. 2009. Bermuda grass. In: Genetic resources, chromosome engineering and crop improvement. CRC Press, New York 5:289.

Yang J, Miao CY, Mao RL, Li Y. 2017. Landscape population genomics of forsythia (Forsythia suspensa) reveal that ecological habitats determine the adaptive evolution of species. Front in Plant Science 8:481.

Yeh FC, Yang RC, Boyle T, Ye ZH, Mao JX. 1997. POPGENE, the user friendly shareware for population genetic analysis. Molecular Biology and Biotechnology Center, University of Alberta: Edmonton, AB, Canada.

Yeh FC, Young RC, Boyle T. 1999. Microsoft Window-based Freeware for Population Genetic Analysis (POPGENE, Ver. 1.31). ftp://ftp.microsoft.com/softlib/mslfiles/hpgl.exe

Zhang JX, Wang ML, Guo ZP, Guan YZ, Guo YX, Yan XB. 2018. Variations in morphological traits of bermudagrass and relationship with soil and climate along latitudinal gradients. Hereditas 155(1):31.

Zhang JX, Wang ML, Guo ZP, Guan YZ, Liu JY, Yan XB, Guo YX. 2019. Genetic diversity and population structure of bermudagrass [Cynodon dactylon (L.) Pers.] along latitudinal gradients and the relationship with polyploidy level. Diversity 11(8):135.

Zhang JX, Wang ML, Guo ZP, Guan YZ, Guo YX, Yan XB. 2020. Variation in ploidy level and genome size of Cynodon dactylon (L.) Pers. along a latitudinal gradient. Folia Geobotanica 2020:1-12.

Zhang R, Liu T, Zhang JL, Sun QM. 2016. Spatial and environmental determinants of plant species diversity in a temperate desert. Journal of Plant Ecology 9(2):124-131.

Zheng Y, Xu S, Liu J, Zhao Y, Liu J. 2017. Genetic diversity and population structure of Chinese natural bermudagrass [Cynodon dactylon (L.) Pers.] germplasm based on SRAP markers. PLoS ONE 12(5): 
649

650

651

652

\section{Figure legends}

654 Fig. 1 Locations of sampled populations of $C$. dactylon. The blue dots represent the sampling sites 655 along longitude gradients.

656

657

658

659

660

661

662

663

664

665

666

667

668

669

670

671

672 Fig. 6 The UPGMA (unweight pair-group method with arithmetic means) dendrogram of 673 bermudagrass groups with di $\square$ erent ploidy level.

674

675 Fig. 7 Regression analysis between ploidy level of bermudagrass (C. dactylon) and longitude. 
Figure 1

Locations of sampled populations of $C$. dactylon.

Fig. 1 Locations of sampled populations of $C$. dactylon. The blue dot represents the sampling sites along longitudinal gradient.

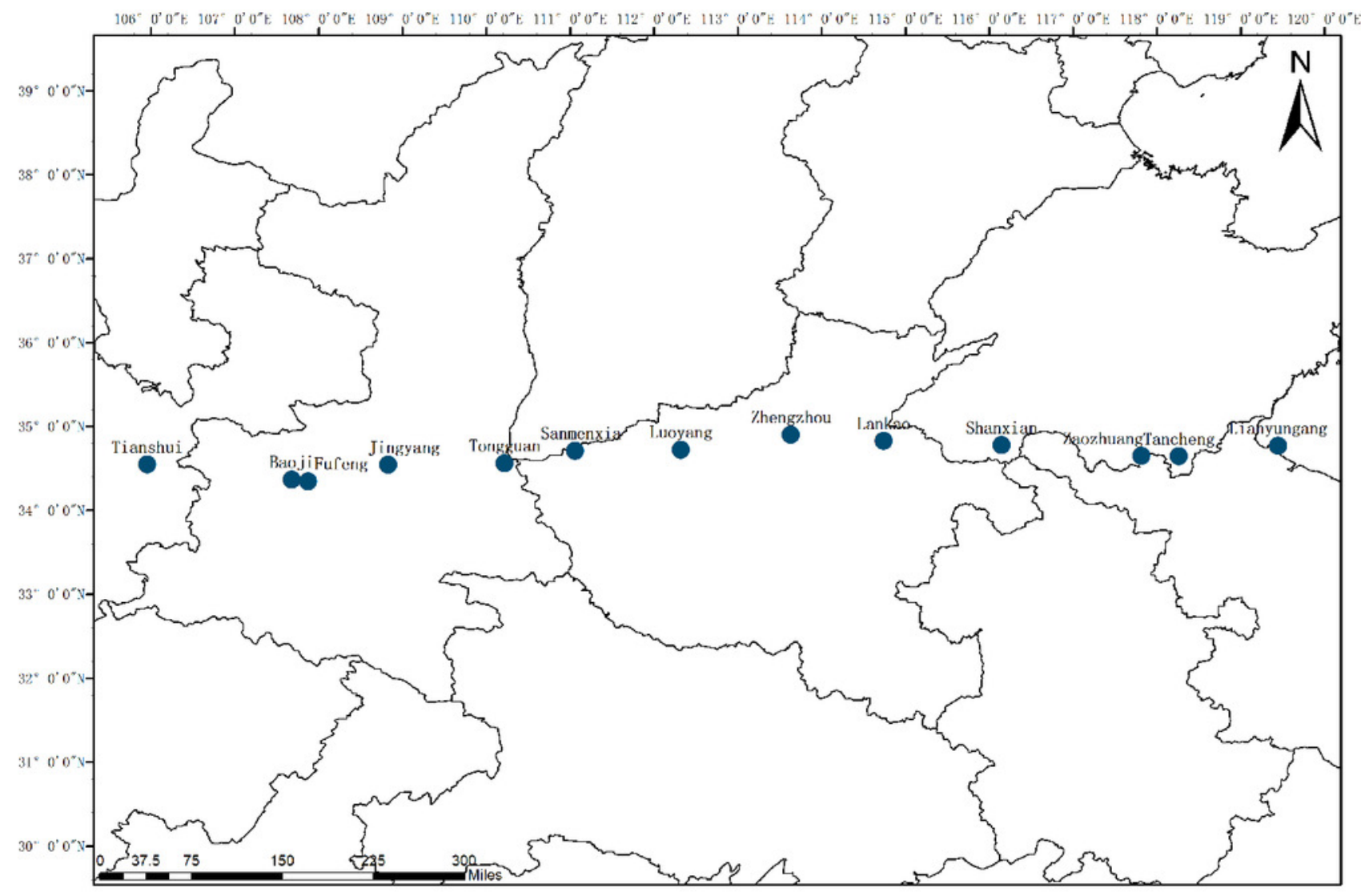


Figure 2

Summary statistics of within-population genetic variation of $13 \mathrm{C}$. dactylon populations from estern to western.

Fig. 2 Summary statistics of within-population genetic variation of $13 \mathrm{C}$. dactylon populations from estern to western. He: Nei's gene diversity index; I: Shannon diversity index.

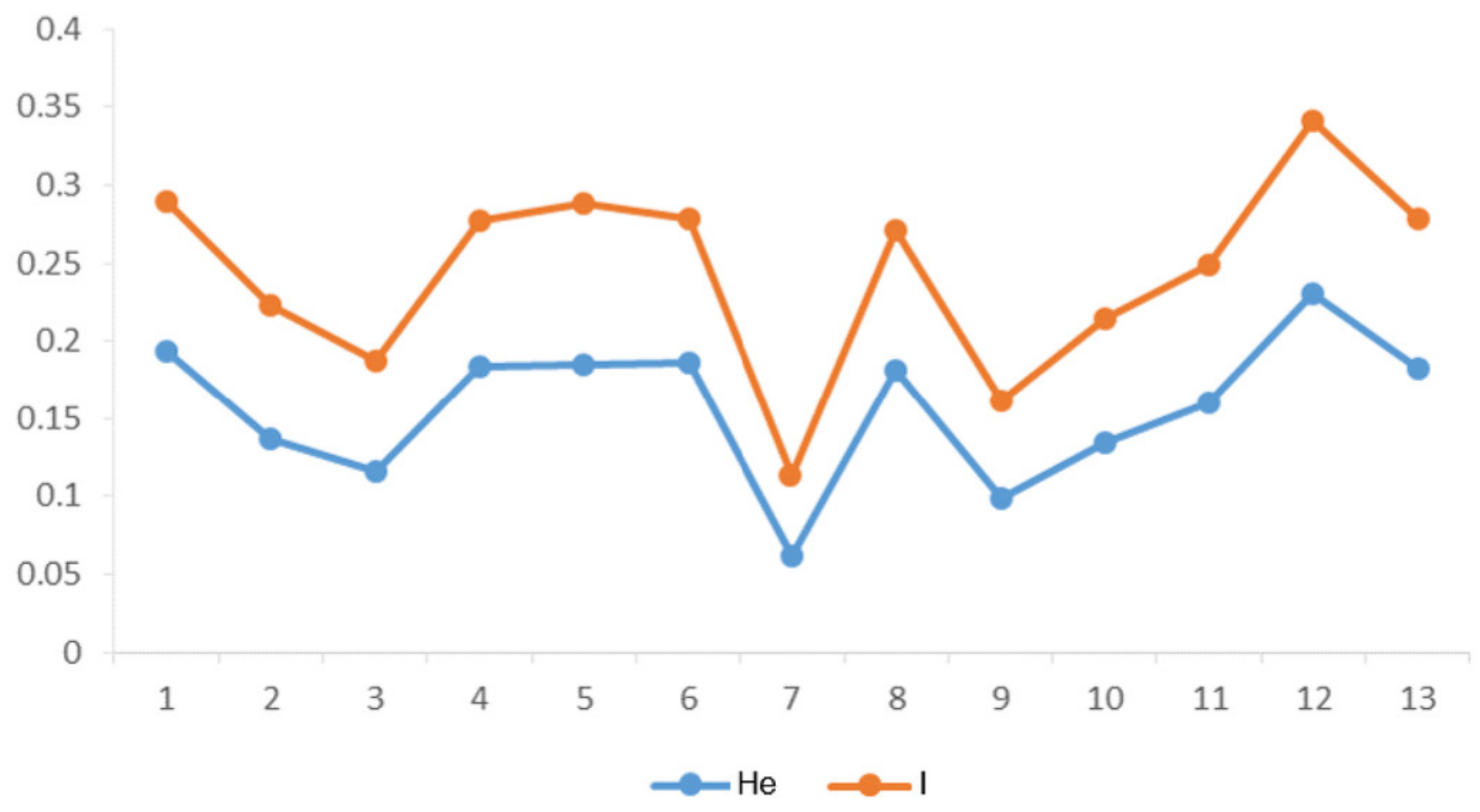


Figure 3

The UPGMA (unweight pair-group method with arithmetic means) dendrogram generated cluster analysis based on EST-SSR data of 13 C. dactylon populations.

Fig. 3 The UPGMA (unweight pair-group method with arithmetic means) dendrogram generated cluster analysis based on EST-SSR data of 13 C. dactylon populations. The $C$. dactylon populations in this study were grouped into three clusters (blue, red, green).

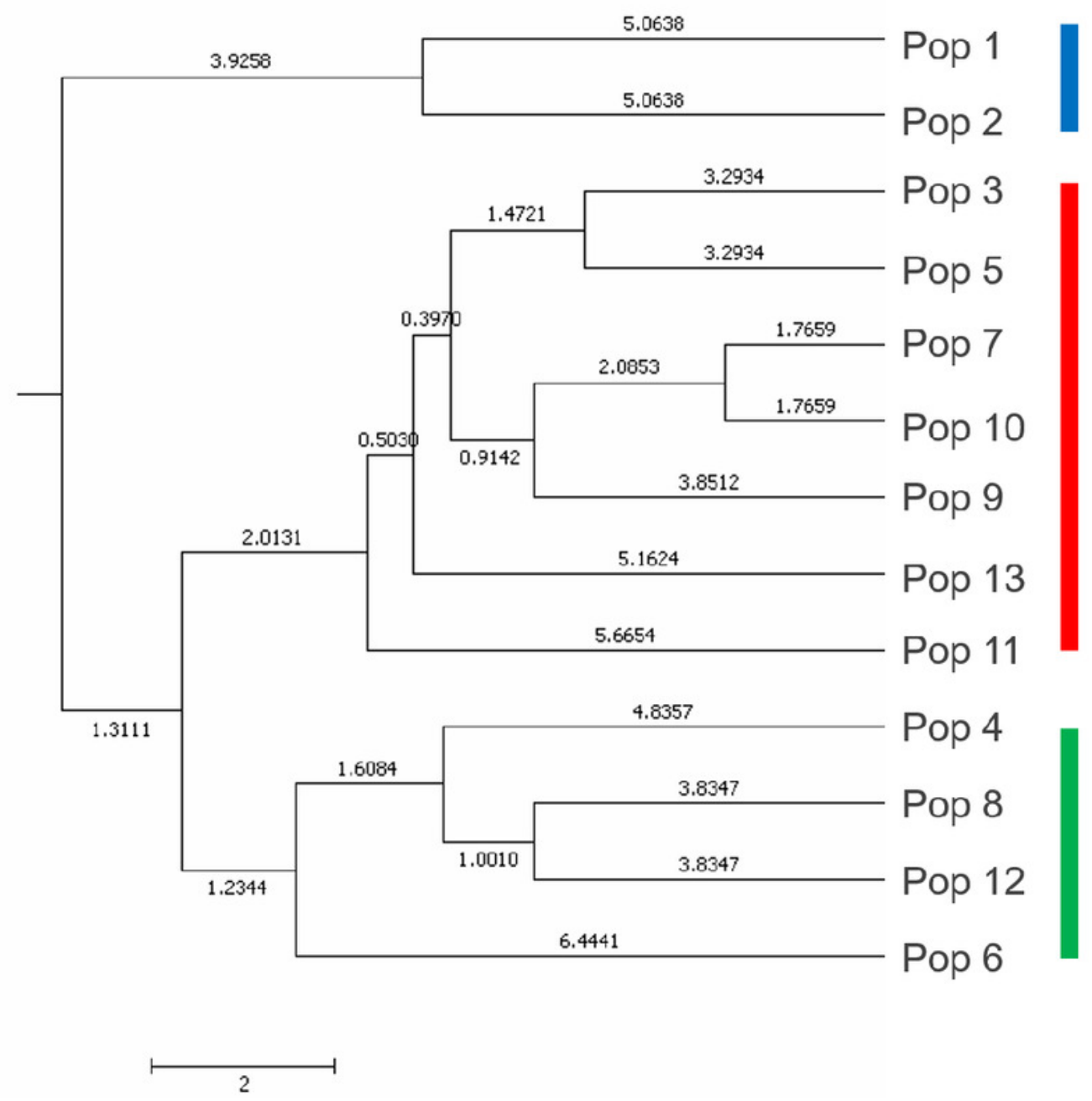

Cluster 1

Cluster 2

Cluster 3 
Figure 4

Principal component analysis of the 13 populations based on the genetic distance derived from EST-SSR markers.

Fig. 4 Principal component analysis of the 13 populations based on the genetic distance derived from EST-SSR markers. Populations in this study were grouped into three clusters (black circles).

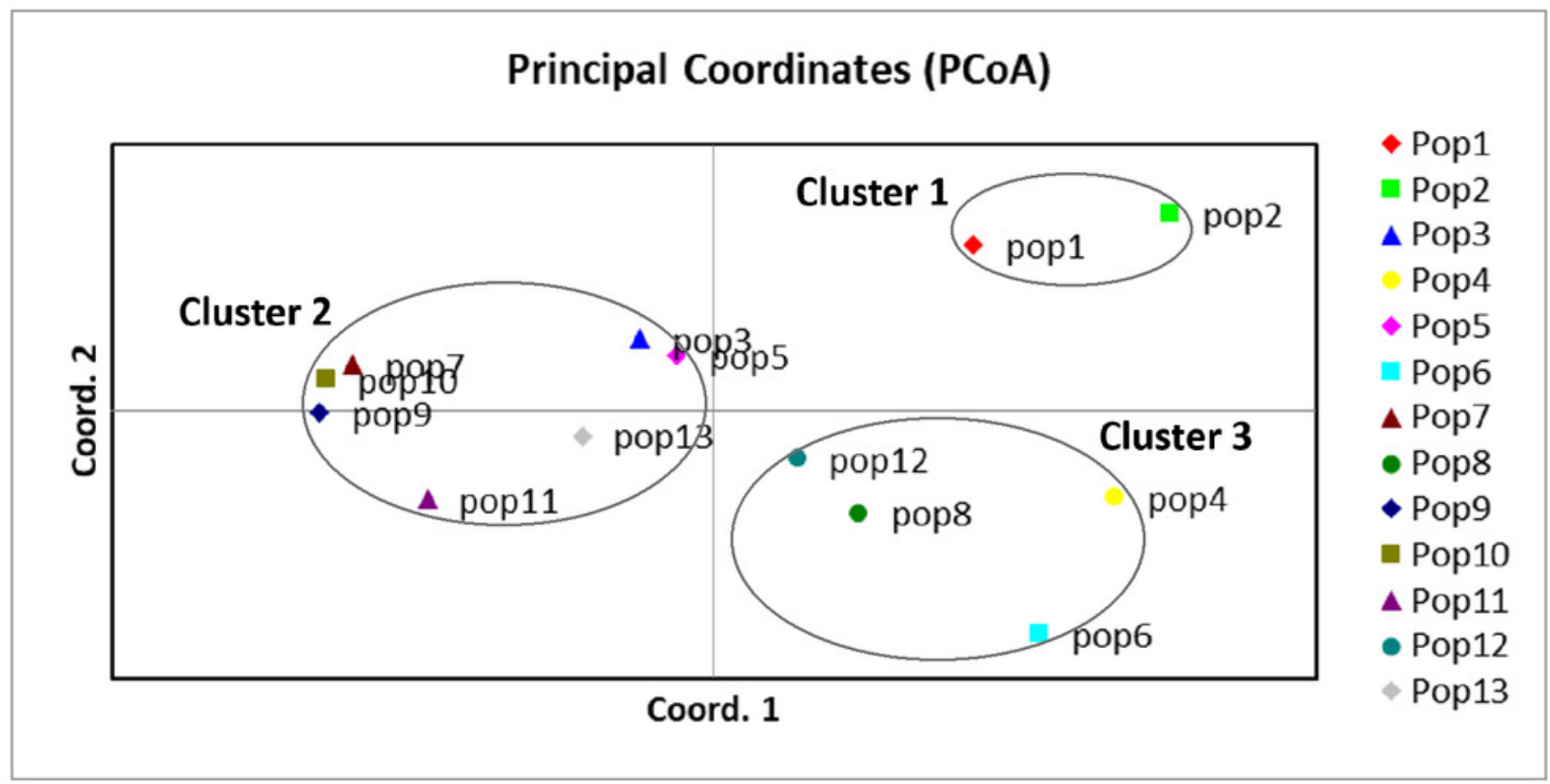




\section{Figure 5}

Population structure analysis of $249 \mathrm{C}$. dactylon plants sampled from 13 populations using the model-based program STRUCTUREas follows: $\mathrm{A}-\mathrm{K}=4$ and $\mathrm{B}-\mathrm{K}=8$.

Fig. 5 Population structure analysis of 249 C. dactylon plants sampled from 13 populations using the model-based program STRUCTUREas follows: $\mathbf{A}-\mathrm{K}=4$ and $\mathbf{B}-\mathrm{K}=8$. Each color shows one Bayesian ancestry group $(K)$ and the length of the colored segment represents the estimated membership proportions in different Bayesian ancestry groups (K).

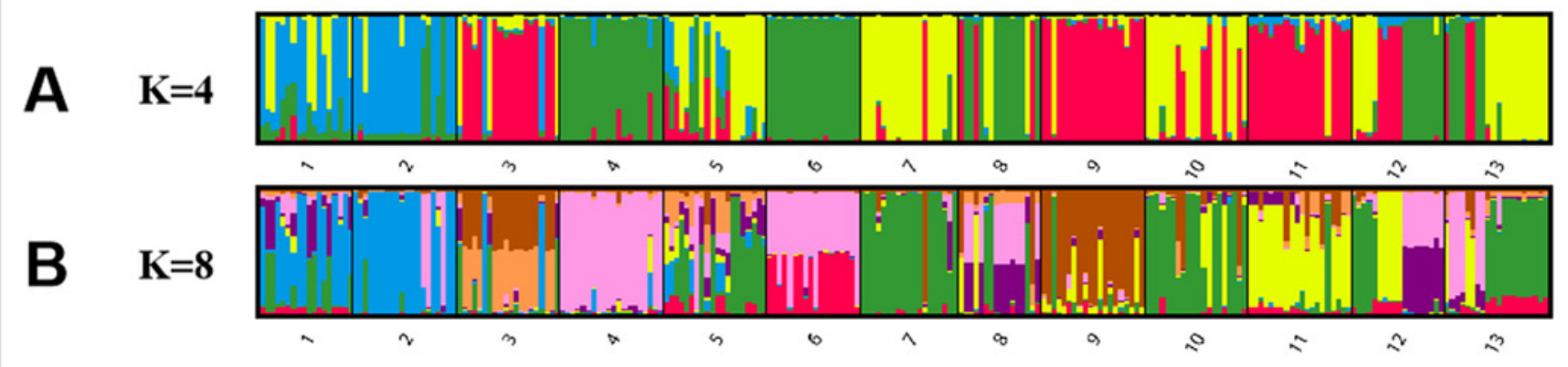


Figure 6

The UPGMA (unweight pair-group method with arithmetic means) dendrogram of bermudagrass groups with different ploidy level.

Fig. 6 The UPGMA (unweight pair-group method with arithmetic means) dendrogram of bermudagrass groups with different ploidy level.

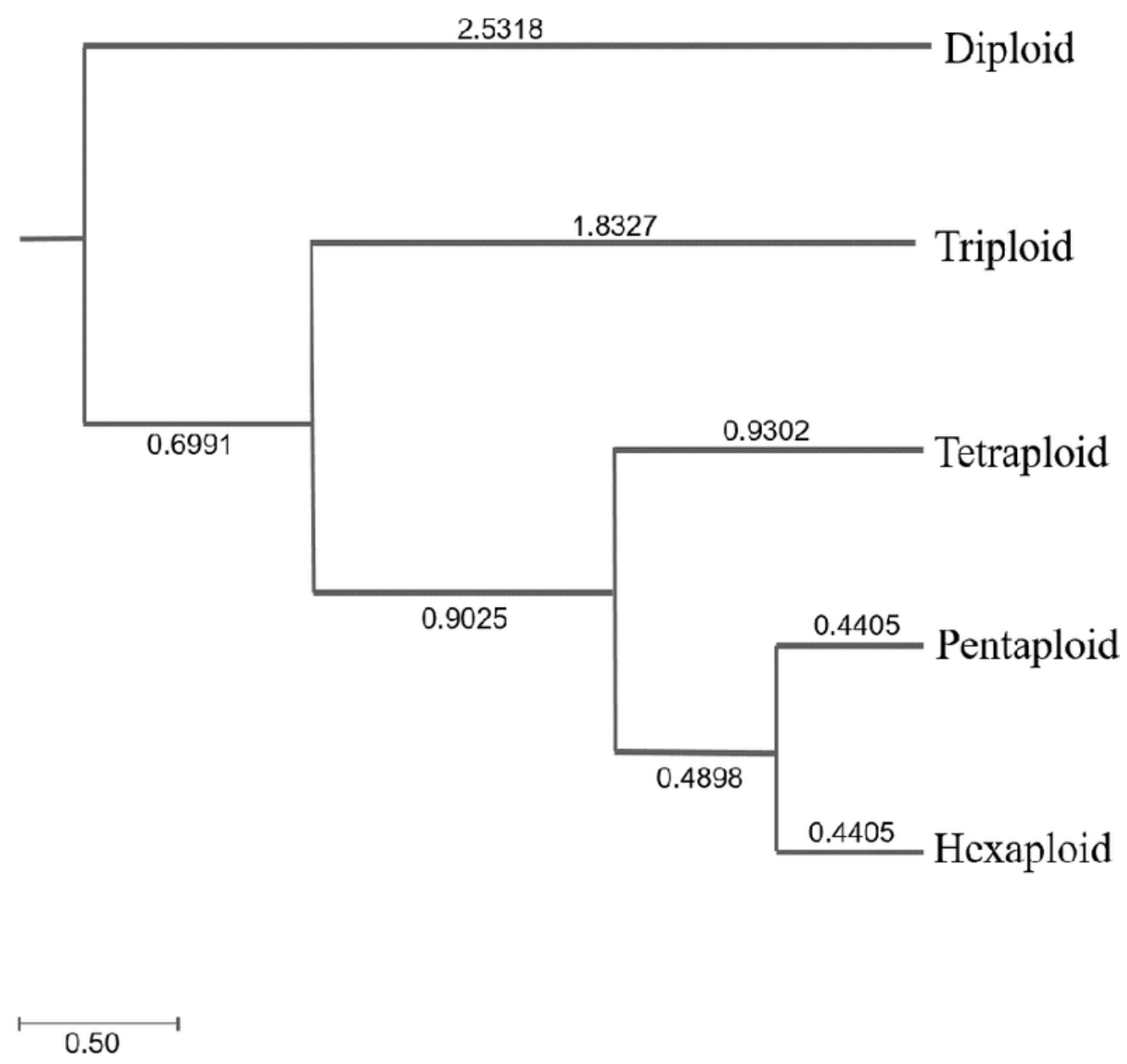


Figure 7

Regression analysis between ploidy level of bermudagrass (C. dactylon) and longitude.

Fig.7 Regression analysis between ploidy level of bermudagrass (C. dactylon) and longitude.

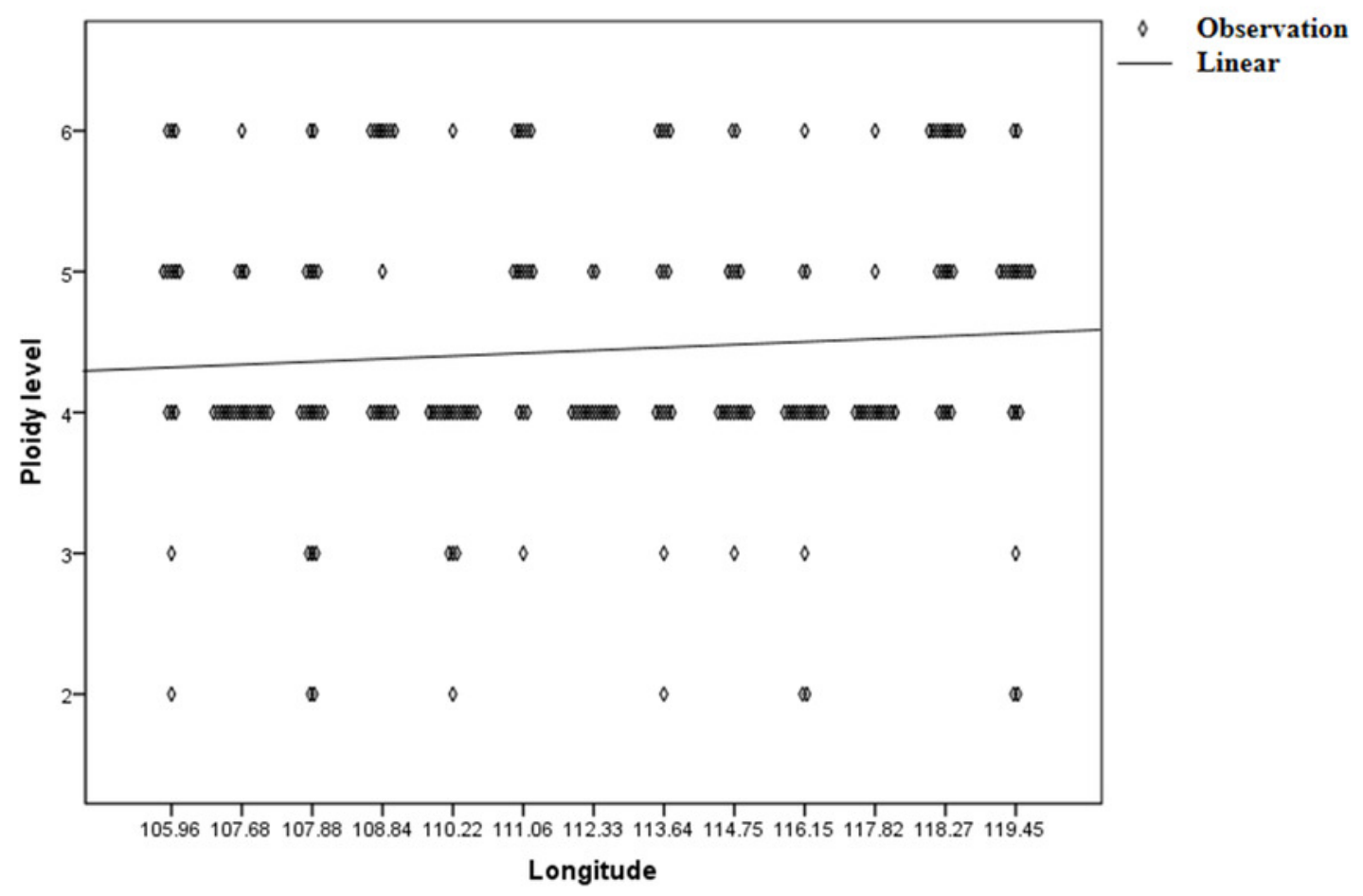




\section{Table $\mathbf{1}$ (on next page)}

Information on geographical sites and climate of $C$. dactylon populations collected from different longitudes in China. 
1 Table 1 Information on geographical sites and climate of C. dactylon populations collected from 2 different longitudes in China.

\begin{tabular}{llllllll}
\hline Code & Region & Habitat & Longitude & Latitude & Altitude & MAT & MAP \\
& & & $(\mathrm{E})$ & $(\mathrm{N})$ & $(\mathrm{m})$ & $\left({ }^{\circ} \mathrm{C}\right)$ & $(\mathrm{mm})$ \\
\hline 1 & Lianyungang & Island & $119^{\circ} 27^{\prime} 06^{\prime \prime}$ & $34^{\circ} 46^{\prime} 09^{\prime \prime}$ & 50 & 14.5 & 883.9 \\
2 & Tancheng & Roadside & $118^{\circ} 16^{\prime} 08^{\prime \prime}$ & $34^{\circ} 38^{\prime} 37^{\prime \prime}$ & 30 & 13.8 & 832.9 \\
3 & Zaozhuang & Roadside & $117^{\circ} 49^{\prime} 20^{\prime \prime}$ & $34^{\circ} 38^{\prime} 48^{\prime \prime}$ & 89 & 14.4 & 820.3 \\
4 & Shanxian & Roadside & $116^{\circ} 09^{\prime} 11^{\prime \prime}$ & $34^{\circ} 46^{\prime} 31^{\prime \prime}$ & 30 & 14.2 & 621.4 \\
5 & Lankao & Roadside & $114^{\circ} 44^{\prime} 55^{\prime \prime}$ & $34^{\circ} 49^{\prime} 32^{\prime \prime}$ & 60 & 14.3 & 631.1 \\
6 & Zhengzhou & Swamp & $113^{\circ} 38^{\prime} 20^{\prime \prime}$ & $34^{\circ} 54^{\prime} 04^{\prime \prime}$ & 90 & 14.7 & 640.8 \\
7 & Luoyang & Roadside & $112^{\circ} 19^{\prime} 30^{\prime \prime}$ & $34^{\circ} 43^{\prime} 20^{\prime \prime}$ & 210 & 14.4 & 637.2 \\
8 & Sanmenxia & Roadside & $111^{\circ} 03^{\prime} 49^{\prime \prime}$ & $34^{\circ} 42^{\prime} 29^{\prime \prime}$ & 340 & 14 & 558.1 \\
9 & Tongguan & Roadside & $110^{\circ} 13^{\prime} 18^{\prime \prime}$ & $34^{\circ} 33^{\prime} 41^{\prime \prime}$ & 540 & 13.1 & 602.9 \\
10 & Jingyang & Roadside & $108^{\circ} 50^{\prime} 07^{\prime \prime}$ & $34^{\circ} 32^{\prime} 32^{\prime \prime}$ & 410 & 13.5 & 504.1 \\
11 & Fufeng & Roadside & $107^{\circ} 52^{\prime} 41^{\prime \prime}$ & $34^{\circ} 20^{\prime} 35^{\prime \prime}$ & 570 & 12.8 & 569.9 \\
12 & Baoji & Ditch side & $107^{\circ} 41^{\prime} 03^{\prime \prime}$ & $34^{\circ} 21^{\prime} 54^{\prime \prime}$ & 630 & 13.5 & 645.9 \\
\hline & Tianshui & Roadside & $105^{\circ} 57^{\prime} 34^{\prime \prime}$ & $34^{\circ} 32^{\prime} 43^{\prime \prime}$ & 1050 & 11.4 & 500.7 \\
\hline
\end{tabular}

3 MAT, mean annual temperature; MAR, mean annual precipitation 4 


\section{Table 2 (on next page)}

Within-population genetic diversity of 13 C. dactylon populations at different longitudes. 
1 Table 2. Within-population genetic diversity of 13 C. dactylon populations at different 2 longitudes.

\begin{tabular}{lllll}
\hline Pop & $\mathrm{N}$ & $\mathrm{He}$ & $\mathrm{I}$ & $\mathrm{PIC}$ \\
\hline 1 & 18 & 0.1939 & 0.2895 & 0.55 \\
2 & 20 & 0.1367 & 0.2231 & 0.56 \\
3 & 20 & 0.1157 & 0.1872 & 0.47 \\
4 & 20 & 0.1837 & 0.2769 & 0.57 \\
5 & 20 & 0.1843 & 0.2878 & 0.68 \\
6 & 18 & 0.1859 & 0.279 & 0.53 \\
7 & 19 & 0.0619 & 0.1131 & 0.40 \\
8 & 16 & 0.1809 & 0.271 & 0.52 \\
9 & 20 & 0.0984 & 0.1617 & 0.43 \\
10 & 20 & 0.1338 & 0.2142 & 0.51 \\
11 & 20 & 0.1603 & 0.2493 & 0.57 \\
12 & 18 & 0.231 & 0.3408 & 0.62 \\
13 & 20 & 0.1818 & 0.2779 & 0.57 \\
Total & 249 & 0.2587 & 0.4029 & 1.00 \\
\hline
\end{tabular}

3 He, Nei's gene diversity index; I, Shannon's diversity index; PIC, Polymorphic information 4 content 


\section{Table 3(on next page)}

Analysis of molecular variance (AMOVA) of based on 249 individuals from the 13 populations of bermudagrass. 
1 Table 3. Analysis of molecular variance (AMOVA) of bermudagrass of different population.

\begin{tabular}{lllll}
\hline Source of variation & df & Sum of squares & Variance components & Percentage of variation \\
\hline Among populations & 12 & 1336.521 & 5.364 & $38.23 \%$ \\
Within populations & 236 & 2045.455 & 8.667 & $61.77 \%$ \\
Total & 248 & 3381.976 & 14.031 & \\
\hline
\end{tabular}

2 Note: df, Degree of freedom

3

4

5

6 


\section{Table 4 (on next page)}

Results of the mismatch distribution analysis and neutrality tests of $C$. dactylon of each population along longitudinal gradients.

Results of the mismatch distribution analysis and neutrality tests of $C$. dactylon of each population along longitudinal gradients. SSD, sum of squared deviation under expansion model; HRI, raggedness; *Significant $(P \leq 0.05)$; **highly significant $(P \leq 0.01)$. 


\begin{tabular}{lllllllllll}
\hline Populations & Tau $(\tau)$ & $\begin{array}{l}\text { Time since } \\
\text { expansion } \\
\text { began(t, Ma) }\end{array}$ & SSD & P-value & HRI & P-value & Fu's FS & P-value & Tajima's D & P-value \\
\hline 1 & 29.500 & 21.612 & 0.006 & 0.960 & 0.013 & 0.820 & -5.704 & $0.017^{*}$ & 1.152 & 0.916 \\
2 & 0.000 & 0.000 & 0.013 & 1.000 & 0.017 & 0.940 & -9.177 & $0.000^{* *}$ & -0.370 & 0.377 \\
3 & 2.000 & 1.465 & 0.008 & 0.870 & 0.011 & 0.810 & -10.399 & $0.001^{* *}$ & -0.299 & 0.435 \\
4 & 16.000 & 11.722 & 0.005 & 0.390 & 0.009 & 0.610 & -7.288 & $0.002^{* *}$ & 0.813 & 0.838 \\
5 & 24.500 & 17.949 & 0.010 & 0.650 & 0.020 & 0.280 & -7.270 & $0.007 * *$ & 0.072 & 0.559 \\
6 & 21.200 & 15.531 & 0.008 & 0.540 & 0.011 & 0.880 & -5.904 & $0.013^{*}$ & 1.116 & 0.888 \\
7 & 0.400 & 0.293 & 0.012 & 0.700 & 0.019 & 0.800 & -14.636 & $0.000^{* *}$ & -1.731 & $0.033^{*}$ \\
8 & 30.400 & 22.271 & 0.023 & 0.340 & 0.020 & 0.670 & -4.805 & $0.017 *$ & 0.944 & 0.881 \\
9 & 2.600 & 1.905 & 0.011 & 0.390 & 0.009 & 0.830 & -11.688 & $0.000^{* *}$ & -0.570 & 0.301 \\
10 & 8.700 & 6.374 & 0.008 & 0.540 & 0.011 & 0.680 & -9.330 & $0.002^{* *}$ & -0.116 & 0.495 \\
11 & 21.500 & 15.751 & 0.004 & 0.900 & 0.007 & 0.960 & -8.116 & $0.004^{* *}$ & 0.194 & 0.619 \\
12 & 35.300 & 25.861 & 0.021 & 0.000 & 0.020 & 0.500 & -4.927 & $0.020^{*}$ & 1.493 & 0.940 \\
13 & 28.900 & 21.172 & 0.009 & 0.780 & 0.016 & 0.560 & -7.349 & $0.002^{* *}$ & 0.762 & 0.840 \\
Mean & 17.003 & 12.457 & 0.011 & 0.620 & 0.014 & 0.718 & -8.199 & $0.007^{* *}$ & 0.266 & 0.625 \\
\hline
\end{tabular}

$3 \mathrm{SSD}$, sum of squared deviation under expansion model; HRI, raggedness; *Significant $(\mathrm{P} \leqslant 0.05)$; * highly significant $(\mathrm{P} \leqslant 0.01)$. 